\title{
Zoneamento de risco climático para cultivo da soja no Cerrado
}

\author{
Ana Clara Alves de MELO ${ }^{*}$, Antonio de Almeida NOBRE JÚNIOR ${ }^{1}$, \\ Fernando Antonio Macena da SILVA², Lucijane Monteiro de ABREU
}

\author{
${ }^{1}$ Universidade de Brasília, Planaltina, DF, Brasil. (ORCID: *; 0000-0001-6068-3331; 0000-0003-2432-8759) \\ ${ }^{2}$ Embrapa Cerrados, Brasília, DF, Brasil. (ORCID: 0000-0003-2329-4059) \\ *E-mail: aanaclaraalvesdemelo@gmail.com (ORCID: 0000-0002-6399-9689)
}

\begin{abstract}
Recebido em: 22/04/2019; Aceito em: 30/09/2019; Publicado em: 04/02/2020.
RESUMO: A agricultura é uma atividade de risco e incerteza. O Zoneamento Agrícola de Risco Climático (ZARC) indica o que, onde e quando plantar para fugir dos eventos climáticos. O objetivo do trabalho foi comparar duas metodologias para o zoneamento agrícola de risco climático da soja (Glycine max (L) Merrill) no Bioma Cerrado. Utilizou-se o Índice de Satisfação da Necessidade de Água (ISNA) considerando às fases fenológicas críticas ao déficit hídrico: Fase I (germinação e emergência) e Fase III (floração e enchimento de grãos). Na primeira abordagem considerou-se a fase III. Na segunda abordagem consideraram-se as fases I e III. Utilizou-se o programa SARRAZON para a simulação do balanço hídrico. A zona de baixo risco climático correspondeu ao ISNA > 0,50 na fase I; e, o ISNA>0,65 na fase III. Para fins de comparação considerou-se a época de semeadura, porcentagem das áreas de risco e quantidade de municípios recomendados. Na segunda metodologia, as zonas de baixo risco foram menores. A soja foi recomendada em solos com maior capacidade de água disponível. As áreas de alto risco situaram-se na transição entre os biomas Caatinga e Pantanal. Esse estudo orienta o risco agroclimático da soja e subsidia políticas públicas no Cerrado.
\end{abstract}

Palavras-chave: agroclimatologia; gestão ambiental; política agrí́cola; planejamento ambiental.

\section{Climatic risk zoning methodologies for soybean cultivation in the Cerrado Biome}

\begin{abstract}
Agriculture is an activity of risk and uncertainty. Agricultural Climate Risk Zoning (ZARC) indicates what, where and when to plant to escape climate events. The objective of this work was to compare two methodologies for agricultural climate risk zoning of soybean (Glycine max (L) Merrill) in the Cerrado Biome. The Water Requirement Satisfaction Index (WRSI) was used considering the phenological phases critical to water deficit: Phase I (germination and emergence) and Phase III (flowering and grain filling). In the first approach, phase III was considered. In the second approach, phases I and III were considered. The SARRAZON program was used to simulate water balance. The low climate risk zone corresponded to WRSI $>0.50$ in phase I; and WRSI $>0.65$ in phase III. For comparison purposes, the sowing time, percentage of risk areas and number of recommended municipalities were considered. In the second methodology, the low risk zones were smaller. Soybean has been recommended in soils with the highest available water capacity. The high-risk areas were in the transition between the Caatinga and Pantanal biomes. This study guides soy agroclimatic risk and subsidizes public policies in the Cerrado.

Keywords: agroclimatology; environmental management; agricultural policy; environmental planning.
\end{abstract}

\section{INTRODUÇÃO}

A agricultura é uma atividade de elevado risco e significativa incerteza. Tais riscos decorrem das ocorrências sanitárias, oscilações do mercado e, principalmente, da instabilidade climática, tais como: secas prolongadas, geadas, excesso de chuvas, inundações e ventos fortes; que têm causado perdas anuais de $\mathrm{R} \$ 11$ bilhões, em média, que corresponde a $1 \%$ do PIB - produto interno bruto agrícola (ARIAS et al., 2015).

Nas últimas décadas, a variabilidade do clima tem causado impactos negativos nos agroecossistemas (IPCC, 2015) e o aumento da temperatura (SILVA et al., 2017) ameaça o cultivo de várias plantas (IPCC, 2007; 2014). No Brasil, as regiões produtoras agrícolas poderão sentir os efeitos negativos da variação do clima (DESCONTO, 2008; PASSOS et al., 2017). As variáveis climáticas se apresentam como fatores de risco agronômico e, o desempenho das culturas depende das condições edafoclimáticas (MACIEL et al., 2009). Recomenda-se avaliação prévia das condições ambientais antes de se iniciar a atividade agrícola, portanto, as indicações das zonas de baixo risco climático, tipos de solo, ciclo das culturas e épocas de semeaduras favoráveis são imprescindíveis para o sucesso da atividade agrícola (FARIAS et al., 2001; ROSSETTI, 2001; SEDIYAMA et al., 2001).

A partir de 1996, o Ministério da Agricultura, Pecuária e Abastecimento - MAPA, sob a coordenação da Comissão Especial de Recursos, instituiu o Projeto Redução de Riscos Climáticos (ZARC) como referência para os ditames da Política Agrícola, para aplicação do crédito rural e o Programa de Garantia da Atividade Agropecuária PROAGRO (ROSSETI, 2001). 
O Zoneamento Agrícola de Risco Climático (ZARC) é um conjunto de técnicas que visa indicar ao produtor o que, onde e quando plantar na tentativa de fugir dos eventos climáticos generalizados, tais como: seca e chuva em excesso, considerando as características da planta e das condições edafoclimáticas, a partir de metodologia validada pela Embrapa- Empresa Brasileira de Pesquisa Agropecuária (BRASIL, 2017).

As informações relacionadas ao tempo, clima e produtos agrometeorológicos que auxiliam a tomada de decisão por parte dos gestores e dos produtores tem sido cada vez mais crescente (CARAMORI et al., 2016). Devido a sua importância na dieta humana, no consumo por suínos e aves, o financiamento da cultura da soja (Glycine max (L.) Merril) segue as orientações do PROAGRO, isto é, o produtor tem que observar as épocas de semeadura e zonas com menor risco climático recomendas pelo ZARC.

$\mathrm{Na}$ safra 2016/17, a produção mundial de soja foi estimada em 351,3 milhões de toneladas e a área plantada de 121 milhões de hectares (EMBRAPA, 2017); sendo a safra brasileira de 114,1 milhões de toneladas e a área plantada de 33,9 milhões de hectares (CONAB, 2017). A projeção do Governo Federal brasileiro é de 146,5 milhões de toneladas de grãos de soja, e a área plantada chegará a 43,2 milhões de hectares, em 2026/2027 (MAPA, 2017). No bioma Cerrado, a safra 2016/2017 foi de 70,8 milhões de toneladas, a área plantada de 21,7 milhões de hectares (CONAB, 2017) e produtividade média de $3.274 \mathrm{~kg} / \mathrm{ha}$. A soja é a principal commoditie agrícola brasileira, sendo aproximadamente 65\% cultivada no Cerrado.

Destaca-se que a política agrícola do ZARC para o cultivo da soja deve estar em perfeita aderência com a política ambiental, que não permite o plantio de culturas anuais em áreas de preservação permanente, nem o financiamento de atividades agrícolas nas áreas desmatadas ilegalmente (BRASIL, 2012); e, não se recomenda o cultivo anual em solos com teor de argila inferior a $10 \%$ (nos primeiros $50 \mathrm{~cm}$ de profundidade), também, em solos que apresentam profundidade inferior a $50 \mathrm{~cm}$ e que são muito pedregosos (BRASIL, 2008). Assim, o ZARC contribui para que se evitem perdas financeiras e danos ambientais, como o desmatamento em zonas de alto risco.

Os trabalhos sobre o zoneamento agrícola são evidentes avanços alcançados para a sustentabilidade da atividade agrícola, no entanto, fazem-se necessário aperfeiçoar o atual sistema de recomendação para a cultura da soja, de modo a acompanhar as recentes mudanças nos cenários climáticos, agrícolas e socioeconômicos. Novos conceitos relacionados às fases críticas das culturas são importantes para a modelagem do risco e qualidade do sistema de zoneamento agrícola do Brasil.

Feitas essas considerações, o objetivo desse trabalho foi comparar duas abordagens metodológicas para o zoneamento agrícola de risco climático da soja no bioma Cerrado; no intuito de subsidiar a tomada de decisão, com informações sobre as condições para o cultivo da soja em zonas de baixo risco.

\section{MATERIAL E MÉTODOS}

O bioma Cerrado ocupa área de $2.036 .448 \mathrm{~km}^{2}$ na porção central do Brasil, 22\% do território nacional (SANO et al., 2008) e abrange 1.390 municípios (MMA, 2011). Neste trabalho, devido a base cartográfica utilizada, foram avaliados
2.050.553 $\mathrm{km}^{2}$, correspondentes a 1.380 municípios (Figura $1)$.

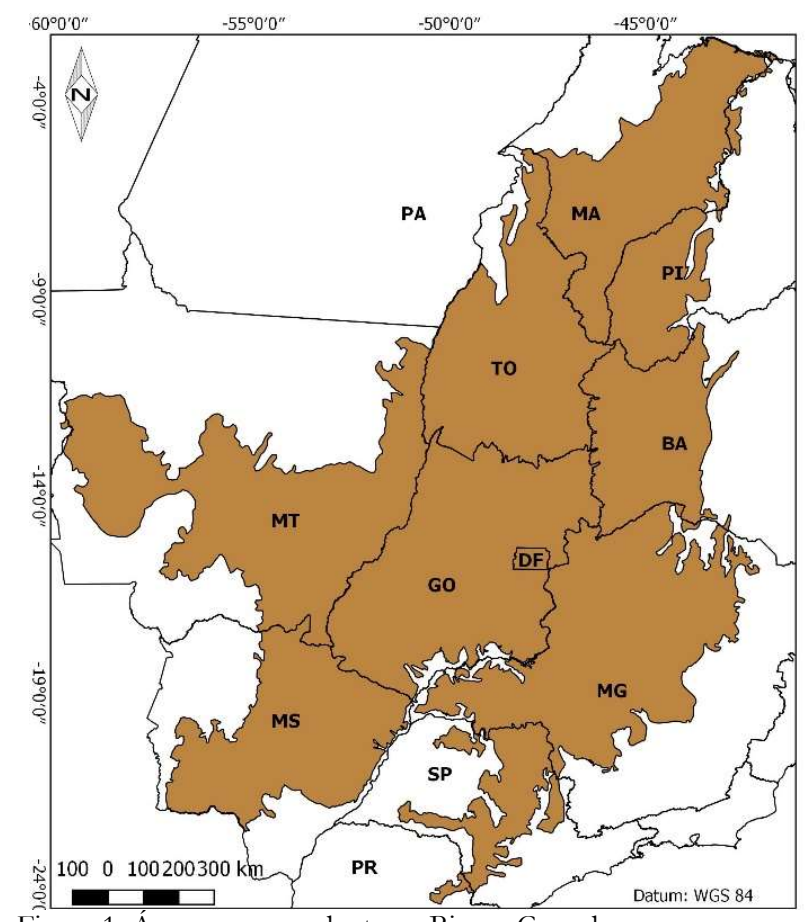

Figura 1. Área correspondente ao Bioma Cerrado. Figure 1. Area corresponding to the Cerrado Biome. Fonte: MMA, 2011

O clima do Cerrado é caracterizado por duas estações bem definidas: uma seca e outra chuvosa. Na classificação climática de Köppen, o clima é do tipo tropical estacional (Aw), na zona Climática A, com precipitação média anual de $1.500 \mathrm{~mm}$, concentrada entre os meses de outubro a março; entretanto, podem ocorrer veranicos, que são períodos de estiagem acompanhados de intenso calor, com duração de uma a três semanas, durante a estação chuvosa, nos meses de janeiro e fevereiro (ALVARES et al., 2014). O período seco, definido em termos de déficit hídrico, ocorre nos meses de abril a setembro, com precipitação total menor que $50 \mathrm{~mm}$. Geralmente, as temperaturas médias são amenas, entre $22^{\circ} \mathrm{C}$ e $27^{\circ} \mathrm{C}$, ao longo do ano (SILVA et al., 2008).

A modelagem e as simulações dos balanços hídricos para a cultura da soja foram realizadas no Laboratório de Biofísica Ambiental da Embrapa Cerrados, em Planaltina - DF. Usouse o Sistema de Análise Regional dos Riscos Agroclimáticos (SARRAZON), que é um modelo agrometeorológico desenvolvido por Baron; Clopes (1996).

O modelo simula o balanço hídrico da cultura com o passo de cálculo diário, a partir de um conjunto de parâmetros que descrevem o solo, a cultura e o clima. O modelo agroclimático parte do pressuposto de que não ocorrerão limitações quanto à fertilidade dos solos e danos às plantas devido à ocorrência de pragas e doenças.

O balanço hídrico foi realizado com base nas seguintes variáveis de entrada:

1) Precipitação pluvial: Foram utilizadas séries temporais de precipitação pluvial com 20 anos de dados diários registrados, no mínimo, entre 1980 a 2010, em 1.253 estações distribuídas espacialmente no Cerrado e em estações próximas ao limite do Bioma. Essas informações foram cedidas pela Agência Nacional das Águas - ANA, Instituto Nacional de Meteorologia - INMET e CAESB, que 
passaram por um processo de consistência e de preenchimento falhas. (Figura 2);

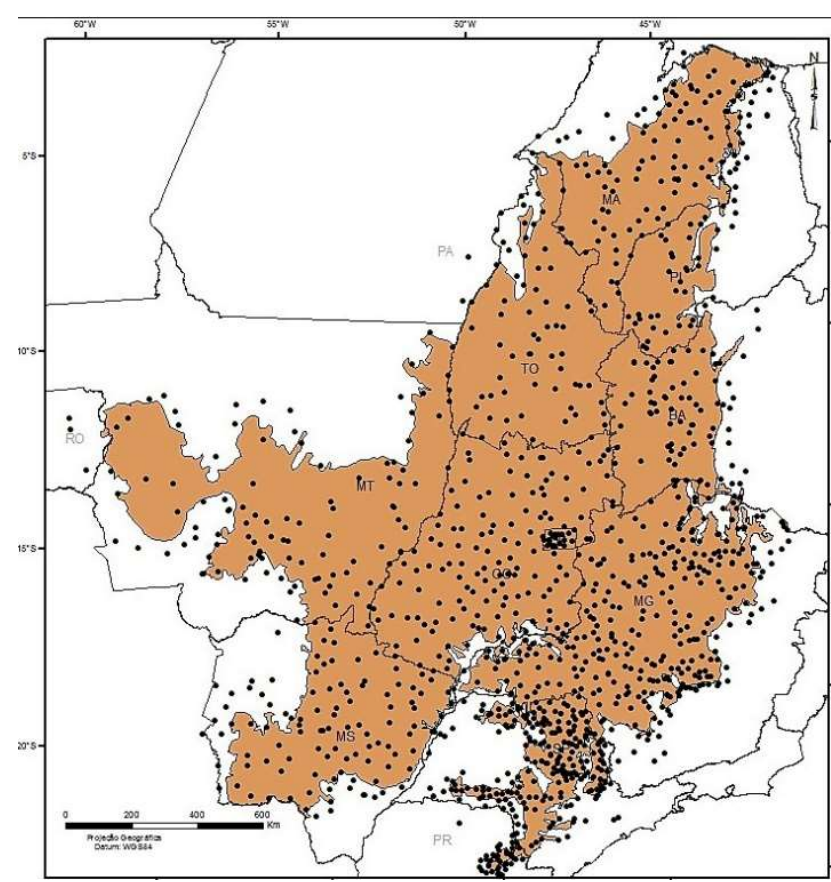

Figura 2. Distribuição espacial das 1.253 estações pluviométricas no bioma Cerrado. Fonte: Elaboração própria (2019)

Figure 2. Spatial distribution of 1,253 pluviometric stations in the Cerrado biome.

2) Evapotranspiração de referência: estimada pelo método de Pennam-Monteith (ALLEN et al., 1998; CARVALHO et al., 2011), a partir de 47 estações climatológicas disponíveis pela ANA, INMET e CAESB ;

3) Ciclo da cultura da soja: consideraram-se cultivares de ciclo precoce (115 dias), ciclo médio (125 dias) e ciclo tardio (140 dias), conforme proposto por Evangelista et al., 2017 ;

4) Fases fenológicas: $\mathrm{O}$ ciclo da planta foi dividido em quatro (4) fases: (i) germinação e emergência, (ii) vegetativa, (iii) floração e enchimento de grãos e (iv) maturação, conforme proposto por Evangelista et al., 2017;

5) Coeficiente de cultura $(\mathrm{Kc})$ : usaram-se valores médios para períodos de dez dias determinados em condições de campo (GUERRA et al., 2005);

6) Reserva útil de água do solo: foram considerados dois tipos de solos: Tipo 2 (T2) e Tipo 3 (T3). O solo do Tipo 2 - foi associado àqueles com textura média, teor de argila entre $15 \%$ e $35 \%$ e a capacidade de água disponível (CAD) de $55 \mathrm{~mm} / \mathrm{m}$; e, o solo Tipo 3 - corresponde aos solos com textura argilosa, teor de argila maior que 35\% e CAD de 75 $\mathrm{mm} / \mathrm{m}$. A reserva útil de água dos solos foi estimada em função da profundidade efetiva do sistema radicular de 50 centímetros.

Para ambos os solos foi considerada o valor limite de 30 $\mathrm{mm}$ de precipitação, acima do qual ocorrem $20 \%$ de escoamento superficial e o restante infiltra no solo. Foram efetuadas simulações para doze épocas de semeadura espaçadas de dez dias (decêndios), entre os meses de outubro a janeiro.

As simulações dos balanços hídricos ocorreram de 30 dias antes da semeadura até 30 dias pós-colheita.
Para cada decêndio de semeadura, o modelo estimou os índices de satisfação da necessidade de água (ISNA), definidos como sendo a relação existente entre evapotranspiração real (ETr) e a evapotranspiração máxima da cultura da cultura da soja (ETm). Em seguida, realizou-se a análise freqüencial, a $80 \%$, dos índices de necessidade de água da soja nas fases críticas. Na primeira metodologia (1M) considerou-se crítica apenas a fase III - de floração e enchimento dos grãos; enquanto que na segunda metodologia (2M) consideraram-se duas fases críticas: Fase I e III.

Os valores do ISNA foram associados à localização geográfica das estações pluviométricas e climáticas para posterior espacialização, utilizando sistema de informação geográfica (Spring versão 5.2.6).

Em tempos de mudança do clima, justifica-se a comparação entre as duas metodológicas para avaliar o risco de déficit hídrico em diferentes fases de crescimento e desenvolvimento da soja.

Nesse estudo, portanto, a definição das zonas de maior ou de menor risco climático foi associada a duas abordagens metodológicas ( $1 \mathrm{M}$ e $2 \mathrm{M})$ :

a) Primeira abordagem $(1 \mathrm{M})$ - usou-se a metodologia do Ministério da Agricultura, Pecuária e Abastecimento (MAPA) adotada para orientar os ditames da atual Política Agrícola Nacional. Nesse caso, a definição das zonas de maior ou de menor risco climático foi associada à ocorrência de déficit hídrico apenas na fase fenológica III da cultura de soja, que corresponde à floração e enchimento de grãos, considerada a mais sensível. Estabeleceram-se classes de risco de acordo com o ISNA obtido, por exemplo, zona de baixo risco climático corresponde ao ISNA $>0,65$, na fase III (Tabela 1).

b) Segunda abordagem (2M) - a definição das zonas de risco climático foi associada à ocorrência de déficit hídrico em duas fases, ou seja, na fase I, que corresponde germinação e desenvolvimento inicial da cultura, e, também, na fase III, que corresponde à floração e enchimento de grãos. Para isso, estabeleceram-se as quatro classes de risco para a fase I, também, de acordo com o ISNA obtido, por exemplo, na fase I, a zona de baixo risco corresponde àquela com ISNA $>50$ (Tabela 1); sendo que para a fase III foram utilizados os mesmos valores de ISNA da 1M (Tabela 1).

Tabela 1. Risco climático conforme o índice de satisfação de necessidade de água (ISNA) para as fases fenológicas I e III da cultura da soja no Cerrado brasileiro.

Table 1. Climatic risk according to the water need satisfaction index (WRSI) for the phenological phases I and III of the soybean crop in the Brazilian Cerrado.

\begin{tabular}{lcc}
\hline \multicolumn{1}{c}{ Risco } & Fase I & Fase III \\
\hline Baixo & ISNA $>0,5$ & ISNA $>0,65$ \\
Médio & $0,5>$ ISNA $>0,40$ & $0,65>$ ISNA $>0,55$ \\
Alto & ISNA $<0,4$ & ISNA $<0,55$ \\
\hline
\end{tabular}

$\mathrm{Na} 2 \mathrm{M}$, ainda, para definição da zona de risco, realizaramse os cruzamentos dos riscos climáticos das fases I e III, de acordo com os critérios adotados na Tabela 2.

Para a recomendação das datas de semeadura favoráveis, para ambas as metodologias, reitera-se que se considerou aqueles decêndios que alcançaram $80 \%$ de ocorrência de probabilidade de a disponibilidade hídrica estar acima dos limites indicados pelo ISNA, para a classe de baixo risco 
climático (SILVA et al., 2017), porque resultariam em menor probabilidade de perdas por estresse hídrico, também para a 2M, conforme apresentado na Tabela 2.

Tabela 2. Definição da classe de risco climático para segunda abordagem (2M).

Table 2. Definition of the climate risk class for the second approach (2M).

\begin{tabular}{lccc}
\hline Riscos & \multicolumn{3}{c}{ Risco da Fase I } \\
\cline { 2 - 3 } Fase III & Baixo & Médio & Alto \\
\cline { 2 - 3 }$(\downarrow)$ & \multicolumn{2}{c}{ Resultado do Cruzamento dos Riscos } \\
\hline Baixo & Baixo & Médio & Alto \\
Médio & Médio & Médio & Alto \\
Alto & Alto & Alto & Alto \\
\hline
\end{tabular}

Ainda, para a análise dos períodos mais favoráveis ao plantio da soja no bioma Cerrado, foi arbitrado que os decêndios que corresponderam a, no mínimo, 70\% da área do Cerrado classificada como zona de baixo risco climático conFigurariam o que se denominou de 'janela de semeadura'.

E, para a recomendação do plantio da soja em determinado município localizado no bioma Cerrado, esse foi recomendado quando, no mínimo, $20 \%$ do território municipal foram classificados como zona de baixo risco climático, conforme a Política Agrícola de Risco Climático (BRASIL, 2017) e dos dados publicados por Evangelista et al., 2017, em determinado decêndio; considerando-se, também, o ciclo da cultivar e tipo de solo.

Nas análises comparativas entre as duas metodologias (1M x 2M), os seguintes aspectos foram discutidos: (i) Diferença de área das zonas de classes de risco; e, (ii) Quantidade de municípios recomendados e não recomendados.

\section{RESULTADOS}

Primeiramente, foram apresentados os dados e a discussão da primeira abordagem metodológica (1M). Em segundo lugar, os resultados da segunda metodologia (2M). E, por fim, apresenta-se a comparação entre as duas metodologias $(1 \mathrm{M} \times 2 \mathrm{M})$.

As análises das interações entre os 12 decêndios de semeadura, os três ciclos das cultivares (precoce, médio, tardio), os dois tipos de solos (T2, T3) e as duas metodologias $(1 \mathrm{M}$ e $2 \mathrm{M})$ geraram 144 mapas; cujos resultados foram sistematizados em duas Tabelas (Tabelas 3 e 4), onde as zonas de riscos foram apresentadas em termos de percentual da área do Cerrado. E, também, foram tabuladas as diferenças de áreas das zonas de risco entre as duas metodologias (Tabela 5). Para ilustração dos resultados foram apresentados apenas dois mapas (Figuras 3 e 4).

Para a recomendação do cultivo nos 1.380 municípios estudados, foram elaboradas duas Tabelas (de dupla entrada), uma para cada metodologia. Cada Tabela contém 1.391 linhas e sete (7) colunas, que resultou em matrizes de 9.737 células. No cruzamento entre as linhas e as colunas foram registrados os períodos de semeadura recomendados para cada município (matrizes não mostradas); entretanto, foi elaborada uma Tabela simplificada da quantidade municípios recomendados e sem recomendação (Tabela 6).

\subsection{Primeira metodologia: a fase III de floração e enchimento crítica}

Para a análise do zoneamento agrícola de risco climático pela primeira abordagem metodológica $(1 \mathrm{M})$, foram apresentados os percentuais da área de Cerrado classificados em zonas de risco (Tabela 3).

Tabela 3. Porcentagem das áreas de risco climático do bioma Cerrado, simuladas para a soja de ciclo precoce, médio e tardio cultivada em dois tipos de solos e semeada em doze decêndios diferentes, considerando a metodologia de déficit hídrico crítico apenas na Fase III floração e enchimento dos grãos.

Table 3. Percentage of the climatic risk areas of the Cerrado biome simulated for early, middle and late cycle soybeans cultivated in two types of soils and planted in twelve different dry seasons, considering the methodology of critical water deficit only in Phase III - flowering and filling the beans.

\begin{tabular}{|c|c|c|c|c|c|c|c|c|c|c|c|c|c|c|}
\hline \multirow{4}{*}{$\begin{array}{c}\text { Ciclo } \\
\mathrm{da} \\
\text { Cultivar }\end{array}$} & \multirow{4}{*}{$\begin{array}{c}\text { Tipo } \\
\text { de } \\
\text { Solo }\end{array}$} & \multirow{4}{*}{$\begin{array}{c}\text { Classe de } \\
\text { Risco }\end{array}$} & \multicolumn{12}{|c|}{ Decêndios de Semeadura } \\
\hline & & & \multicolumn{3}{|c|}{ Outubro } & \multicolumn{3}{|c|}{ Novembro } & \multicolumn{3}{|c|}{ Dezembro } & \multicolumn{3}{|c|}{ Janeiro } \\
\hline & & & 5 & 15 & 25 & 5 & 15 & 25 & 5 & 15 & 25 & 5 & 15 & 25 \\
\hline & & & \multicolumn{12}{|c|}{ Percentual de Área do Bioma Cerrado } \\
\hline \multirow{6}{*}{ Precoce } & \multirow{3}{*}{$\mathrm{T} 2 *$} & Baixo & 64 & 67 & 63 & 65 & 63 & 67 & 64 & 68 & 71 & 67 & 62 & 47 \\
\hline & & Médio & 9 & 9 & 12 & 12 & 16 & 15 & 14 & 11 & 12 & 14 & 14 & 20 \\
\hline & & Alto & 27 & 25 & 25 & 23 & 21 & 18 & 22 & 21 & 17 & 19 & 24 & 33 \\
\hline & \multirow{3}{*}{ T3** } & Baixo & 68 & 71 & 73 & 72 & 72 & 73 & 75 & 77 & 78 & 76 & 71 & 65 \\
\hline & & Médio & 11 & 12 & 14 & 16 & 14 & 11 & 9 & 8 & 8 & 10 & 12 & 12 \\
\hline & & Alto & 21 & 17 & 13 & 12 & 14 & 16 & 16 & 15 & 14 & 14 & 17 & 23 \\
\hline \multirow{6}{*}{ Médio } & \multirow{3}{*}{$\mathrm{T} 2$} & Baixo & 68 & 69 & 68 & 65 & 65 & 67 & 69 & 70 & 68 & 63 & 51 & 33 \\
\hline & & Médio & 10 & 13 & 12 & 16 & 16 & 14 & 12 & 12 & 14 & 14 & 19 & 22 \\
\hline & & Alto & 22 & 12 & 20 & 19 & 19 & 19 & 19 & 18 & 18 & 23 & 30 & 45 \\
\hline & \multirow{3}{*}{ T3 } & Baixo & 78 & 74 & 74 & 72 & 76 & 77 & 77 & 79 & 77 & 74 & 67 & 50 \\
\hline & & Médio & 9 & 14 & 16 & 15 & 10 & 9 & 8 & 8 & 10 & 11 & 13 & 23 \\
\hline & & Alto & 13 & 18 & 10 & 13 & 14 & 14 & 15 & 13 & 13 & 15 & 20 & 27 \\
\hline \multirow{6}{*}{ Tardio } & \multirow{3}{*}{$\mathrm{T} 2$} & Baixo & 69 & 69 & 66 & 67 & 69 & 70 & 72 & 70 & 66 & 55 & 35 & 24 \\
\hline & & Médio & 13 & 13 & 15 & 15 & 13 & 12 & 11 & 13 & 14 & 18 & 25 & 12 \\
\hline & & Alto & 18 & 18 & 19 & 18 & 18 & 18 & 17 & 17 & 20 & 27 & 40 & 64 \\
\hline & \multirow{3}{*}{ T3 } & Baixo & 74 & 74 & 73 & 77 & 78 & 78 & 80 & 80 & 76 & 69 & 59 & 34 \\
\hline & & Médio & 14 & 16 & 16 & 10 & 8 & 8 & 8 & 8 & 10 & 13 & 17 & 25 \\
\hline & & Alto & 12 & 10 & 11 & 13 & 14 & 14 & 12 & 12 & 14 & 18 & 24 & 41 \\
\hline
\end{tabular}

$* \overline{\mathrm{T} 2}=$ Solos de textura média; $* * \mathrm{~T} 3=$ Solos de textura argilosa 
Considerando que os períodos mais favoráveis para a semeadura da soja seriam aqueles decêndios que, no mínimo, $70 \%$ do bioma Cerrado foram classificados como zonas de baixo risco climático, verificou-se que para cultivar de soja precoce (ciclo de 115 dias) plantada em solo do Tipo 2 (CAD $=55 \mathrm{~mm} / \mathrm{m})$, a melhor data de semeadura foi no decêndio que se inicia em 25 de dezembro (71\%); mas, para essa mesma cultivar precoce em solo do Tipo $3(\mathrm{CAD}=75$ $\mathrm{mm} / \mathrm{m}$ ), a 'janela de semeadura' ampliou-se para o número de 10 decêndios, abrangeu o período entre 15 de outubro até 15 de janeiro (Tabela 3).

Para a soja de ciclo médio (125 dias) em solo do Tipo 2, a melhor data de semeadura foi no decêndio de 15 de dezembro (70\%); mas, para essa cultivar em solo Tipo 3, verificou-se a 'janela de semeadura' de 10 decêndios favoráveis, abrangendo o período de 05 de outubro a 05 de janeiro.

Para a soja de ciclo tardio (140 dias) no solo Tipo 2, a janela de semeadura de baixo risco foi constituída de três decêndios, entre os períodos de 25 de novembro a 15 de dezembro; e, em solo do Tipo 3, a janela de semeadura de baixo risco climático correspondeu a 10 decêndios, no período de 05 de outubro a 25 de dezembro.

Estes resultados indicaram variações de risco em função dos decêndios de semeadura, ciclo da cultivar e capacidade de água disponível no solo; sendo que os menores riscos foram em solos do Tipo $3(\mathrm{CAD}=75 \mathrm{~mm} / \mathrm{m})$, com maior disponibilidade de água, independente do ciclo da soja.

Nesta primeira abordagem metodológica $(1 \mathrm{M})$, verificouse a ocorrência de 34 decêndios favoráveis à semeadura (Tabela 3); ou seja, as cultivares de ciclo precoce e de médio, ambas em solos do Tipo 3, apresentaram o número da ocorrência de 10 decêndios favoráveis à semeadura com baixo risco climático; e, em solo do Tipo 2 essas duas cultivares apresentaram, cada uma delas, apenas a ocorrência favorável de 1 decêndio. E, a cultivar de ciclo tardio em solo Tipo 3 apresentou a ocorrência de 9 decêndios favoráveis à semeadura com baixo risco climático e, em solo do Tipo 2 apresentou a ocorrência de 3 decêndios com baixo risco climático.

Ressalta-se que cultivar de ciclo tardio em solo Tipo 3 apresentou a maior área para o semeio da soja em $80 \%$ da área do Cerrado em dois decêndios: 05 e 15 de dezembro.

É importante ressaltar que embora recomendou-se o plantio na data de 25 de dezembro, por exemplo para soja do tipo precoce no solo tipo 2, foi por que nesse período, considerando os fatores climáticos, ela vai ter $70 \%$ de probabilidade de sucesso no plantio. Isso não impede de o produtor iniciar o plantio mais cedo, por exemplo, em 15 de dezembro, com $68 \%$ de probabilidade, ou mais tarde, em 5 de janeiro, com $67 \%$ de probabilidade.

Adotou-se o valor de $70 \%$ apenas para fins desse estudo, de forma a trazer uma maior segurança aos dados e ao produtor, pois por se tratar de um estudo a nível de bioma, acaba perdendo as peculiaridades regionais por haver uma generalização dos dados.

Conforme indicado por Evangelista et al. (2017) não se pode afirmar que não se deva ou que não se cultiva esta cultura nessas localidades ou nesses períodos, mas que a frequência de ocorrência de quebras de rendimento por restrição hídrica é superior a $20 \%$, ou seja, mais que dois anos de cultivo em cada dez, e teria como consequência o não acesso ao seguro rural.
Na Figura 3, apresentou-se o mapa das zonas de risco climático para a cultura da soja de ciclo médio (125 dias) em solo do Tipo $3(\mathrm{CAD}=75 \mathrm{~mm} / \mathrm{m})$ e semeadura no decêndio que se inicia em 15 de novembro, onde se verifica que aproximadamente $20 \%$ da área do Cerrado brasileiro foram classificados como zona de alto risco climático (Tabela 3).

As zonas de alto risco climático ocorreram principalmente nos Estados da Bahia, Minas Gerais, Piauí, Maranhão e Mato Grosso do Sul (Figura 3).

Esses resultados corroboram com os obtidos por Evangelista et al. (2017), que afirmaram que a variabilidade temporal e espacial das chuvas, suas interações com as características físico-hídricas dos solos, a demanda de água da cultura, bem como de sua tolerância à restrição hídrica, além da baixa capacidade de retenção de água observaram grande área de alto risco e sem épocas de semeadura da soja sem risco de perdas de rendimento, especialmente no oeste da Bahia e no sul Piaui. Os autores afirmaram ainda, com base nos dados da CONAB (2016) que esta condição foi observada especialmente nos últimos três anos safra, com consideráveis quebras de rendimento das lavouras.

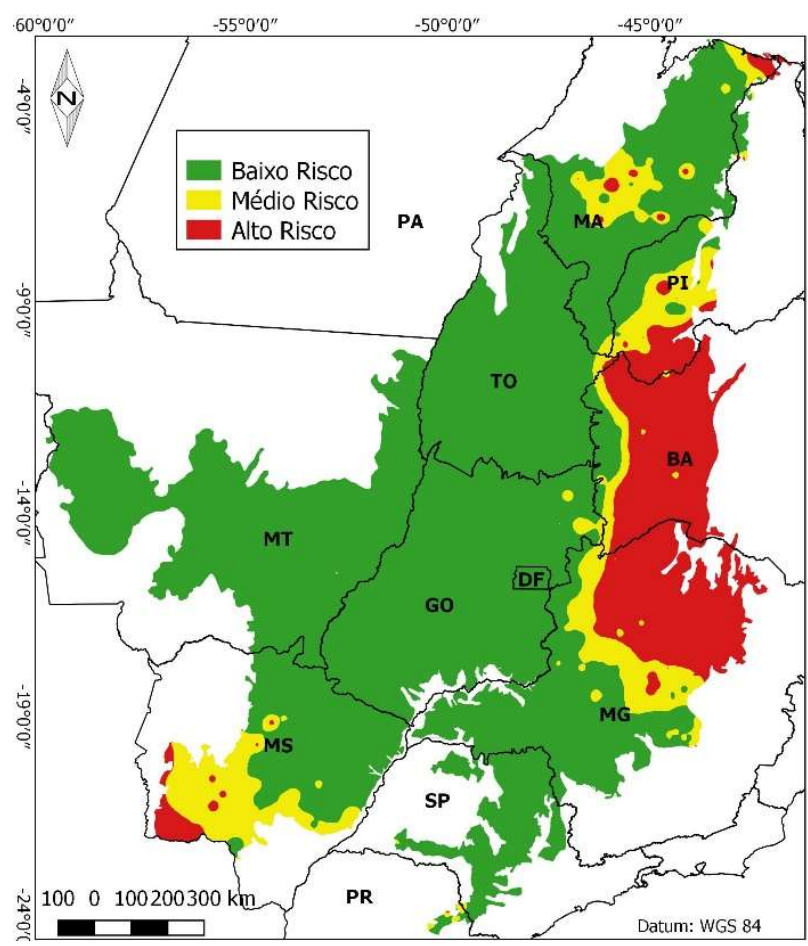

Figura 3. Distribuição espacial do risco climático para a cultivar da soja de ciclo médio (125 dias), semeada em solos com a capacidade de água disponível de $75 \mathrm{~mm} / \mathrm{m}$ (Tipo 3), no decêndio de 15 de novembro, pela metodologia que considerou critico o déficit hídrico apenas na fase de floração e enchimento de grãos (Fase III). Fonte: Elaboração própria (2019)

Figure 3. Spatial distribution of climatic risk for medium-cycle soybean (125 days) cultivated on soils with available water capacity of $75 \mathrm{~mm} / \mathrm{m}$ (Type 3) in the december 15, considered critical the water deficit only in the phase of flowering and filling of grains (Phase III).

Observou-se que a maioria das áreas de alto risco situouse em zonas de transição entre o bioma Cerrado e Caatinga, principalmente, onde as condições agroclimáticas tendem a ser mais restritivas, quando comparados com os ecótonos entre o Cerrado e os biomas Amazônia e Pantanal (Figura 3). 
$\mathrm{Na}$ parte central do bioma Cerrado predominaram as zonas de baixo risco climático, situadas principalmente nos Estados de Goiás, Mato Grosso, Tocantins e no Distrito Federal; enquanto que as zonas de médio e alto risco situaram-se nas regiões dos ecótonos Cerrado-Caatinga e Cerrado-Pantanal (Figura 3). Discute esses resultados afirmando que as características meteorológicas desses biomas, pois possuem uma frequente ocorrência de dias sem chuvas e em secas prolongadas, como no caso da Caatinga (CORREIA et al., 2011) e uma alta variabilidade de chuvas e pulsos de inundação, como no caso do Pantanal (CADAVID, 1984), o que faz com que seja um dos motivos para a sua inclusão nas zonas de altos climático para o plantio da soja.

Quanto às recomendações para os 1.380 municípios estudados no bioma Cerrado, nesta primeira abordagem metodológica, apenas da fase III crítica, foi recomendado o enquadramento de 1.252 municípios para a semeadura da soja de ciclo precoce em solo do Tipo 2, e ainda, 1.272 municípios quando semeada em solo Tipo 3. Para soja de ciclo médio em solo do Tipo 2 foram recomendados 1.231 municípios, e em solo T3 foram recomendados 1.289. E, para a soja de ciclo tardio foram recomendados 1.221 e 1.271 municípios para os solos Tipo 2 e 3 , respectivamente (Tabela 6).

Com relação àqueles municípios que apresentaram zona de baixo risco menor que $20 \%$ da área municipal, que ficaram, portanto, - sem recomendação -, nesta primeira abordagem verificou-se que a cultivar da soja de ciclo tardio (140 dias) plantada em solo do Tipo $2(\mathrm{CAD}=55 \mathrm{~mm} / \mathrm{m})$ correspondeu ao maior número de municípios (159) - sem recomendação -, porque a cultura ficou sujeita a veranicos por maior período de tempo e em solos com menor capacidade de água disponível; em contraste, o menor número de municípios (91) - sem recomendação correspondeu à cultivar de ciclo médio em solo do Tipo 3 (Tabela 6).

\subsection{Segunda metodologia: duas fases críticas - fase I e fase III}

$\mathrm{Na}$ segunda metodologia (2M), os resultados das simulações dos balanços hídricos foram também classificados por zona de risco climático em percentual da área do bioma Cerrado (Tabela 4).

Tabela 4. Percentagem da área de risco do bioma Cerrado, simuladas para a soja de ciclo precoce, médio e tardio, cultivada em dois tipos de solos, semeadas em doze decêndios diferentes, com a metodologia que considera o déficit hídrico crítico na Fase I (germinação e emergência) e na Fase III (floração e enchimento).

Table 4. Percentage of the risk area of the Cerrado biome, simulated for early, middle and late-season soybeans, cultivated in two types of soils, planted in twelve different decades, using the methodology that considers critical water deficit in Phase I (germination and emergence) and Phase III (flowering and filling).

\begin{tabular}{|c|c|c|c|c|c|c|c|c|c|c|c|c|c|c|}
\hline \multirow{4}{*}{$\begin{array}{l}\text { Ciclo da } \\
\text { Cultivar }\end{array}$} & \multirow{4}{*}{$\begin{array}{l}\text { Tipo de } \\
\text { Solo }\end{array}$} & \multirow{4}{*}{$\begin{array}{c}\text { Classe de } \\
\text { Risco }\end{array}$} & \multicolumn{12}{|c|}{ Datas de Semeaduras } \\
\hline & & & \multicolumn{3}{|c|}{ Outubro } & \multicolumn{3}{|c|}{ Novembro } & \multicolumn{3}{|c|}{ Dezembro } & \multicolumn{3}{|c|}{ Janeiro } \\
\hline & & & 5 & 15 & 25 & 5 & 15 & 25 & 5 & 15 & 25 & 5 & 15 & 25 \\
\hline & & & \multicolumn{12}{|c|}{ Percentual de Área do Bioma Cerrado } \\
\hline \multirow{6}{*}{ Precoce } & \multirow{3}{*}{$\mathrm{T} 2$} & Baixo & 39 & 51 & 51 & 65 & 62 & 59 & 50 & 64 & 70 & 65 & 62 & 47 \\
\hline & & Médio & 16 & 11 & 12 & 11 & 13 & 14 & 14 & 12 & 12 & 14 & 12 & 20 \\
\hline & & Alto & 45 & 38 & 37 & 24 & 25 & 27 & 36 & 24 & 18 & 21 & 26 & 33 \\
\hline & \multirow{3}{*}{ T3 } & Baixo & 34 & 51 & 65 & 72 & 70 & 69 & 71 & 73 & 77 & 76 & 71 & 65 \\
\hline & & Médio & 20 & 13 & 10 & 13 & 11 & 11 & 9 & 9 & 9 & 10 & 12 & 12 \\
\hline & & Alto & 46 & 36 & 25 & 15 & 19 & 20 & 20 & 18 & 14 & 14 & 17 & 23 \\
\hline \multirow{6}{*}{ Médio } & \multirow{3}{*}{$\mathrm{T} 2$} & Baixo & 34 & 51 & 64 & 64 & 63 & 63 & 65 & 67 & 67 & 63 & 51 & 33 \\
\hline & & Médio & 19 & 13 & 9 & 12 & 13 & 13 & 12 & 13 & 14 & 14 & 19 & 22 \\
\hline & & Alto & 47 & 36 & 27 & 24 & 24 & 24 & 23 & 20 & 19 & 23 & 30 & 45 \\
\hline & \multirow{3}{*}{ T3 } & Baixo & 40 & 53 & 64 & 70 & 70 & 72 & 72 & 75 & 76 & 74 & 67 & 50 \\
\hline & & Médio & 19 & 13 & 10 & 11 & 10 & 9 & 9 & 9 & 10 & 11 & 13 & 23 \\
\hline & & Alto & 41 & 34 & 26 & 19 & 20 & 19 & 19 & 16 & 14 & 15 & 20 & 27 \\
\hline \multirow{6}{*}{ Tardio } & \multirow{3}{*}{ T2 } & Baixo & 35 & 51 & 64 & 64 & 65 & 66 & 67 & 66 & 65 & 55 & 35 & 24 \\
\hline & & Médio & 20 & 13 & 9 & 12 & 13 & 12 & 12 & 15 & 14 & 18 & 25 & 12 \\
\hline & & Alto & 45 & 36 & 27 & 24 & 22 & 22 & 21 & 19 & 21 & 27 & 40 & 64 \\
\hline & \multirow{3}{*}{ T3 } & Baixo & 37 & 54 & 67 & 71 & 72 & 73 & 76 & 76 & 75 & 69 & 59 & 34 \\
\hline & & Médio & 21 & 12 & 8 & 9 & 9 & 9 & 8 & 9 & 11 & 13 & 17 & 25 \\
\hline & & Alto & 42 & 34 & 25 & 20 & 19 & 18 & 16 & 15 & 14 & 18 & 24 & 41 \\
\hline
\end{tabular}

E, também, considerou-se o período favorável à semeadura quando, no mínimo, $70 \%$ da área do Cerrado foram classificados como zona de baixo risco, sendo assim, essa segunda metodologia (Fases I e III críticas) foi mais restritiva, porque o número de decêndios correspondentes às áreas de baixo risco diminuiu a ocorrência de 34 para 21decêndios favoráveis, na primeira e segunda abordagem metodológica, respectivamente, ou seja, houve uma diminuição de 13 decêndios favoráveis.

Em geral, os maiores porcentuais de área de alto risco ocorreram nas simulações com semeio no início do período chuvoso, contudo, verificou-se que nenhum decêndio foi favorável à semeadura no mês de outubro. As zonas de baixo risco climático passaram a predominar a partir do mês de novembro (Tabela 4).

Para a soja de ciclo precoce em solo Tipo 2, a zona de baixo risco ocorreu somente no semeio do decêndio de 25 de dezembro, mas em solo Tipo 3, a 'janela de semeadura' indicou a ocorrência de sete (7) decêndios favoráveis, entre 05 de novembro a 15 de janeiro. Para cultivar de ciclo médio em solo Tipo 2, nenhum decêndio foi de baixo risco; mas em solo Tipo 3 apresentou sete (7) decêndios favoráveis, no período de 05 de novembro a 05 de janeiro. E, para cultivar de ciclo tardio em solo Tipo 2 , também nenhum decêndio foi 
favorável, mas em solos do Tipo 3 foram verificados seis (6) decêndios favoráveis, entre o período de 05 de novembro a 25 de dezembro (Tabela 4).

Observou-se que o cultivo da soja em solos com maior capacidade de água disponível (Tipo 3, CAD $=75 \mathrm{~mm} / \mathrm{m}$ ) correspondeu à menor probabilidade de perdas por déficit hídrico, tanto na primeira metodologia (Fase III crítica) quanto na segunda abordagem metodológica (Fases I e III críticas), porque garante as necessidades hídricas da cultura por mais tempo, durante os períodos de estiagens, como os veranicos.

Estes resultados corroboram com os dados de diversos autores, tais como o de Farias et al. (2001) que afirmou em seu estudo que solos com baixa capacidade de armazenamento de água apresentaram-se, em geral, impróprios para o cultivo da soja na maioria das regiões, nos diferentes ciclos das cultivares e de épocas de semeadura considerados. Já Evangelista et al. (2017) concluiu em seu estudo sobre o ZARC no Matopiba, que a combinação dos solos de textura argilosa com o grupo de cultivares de soja de ciclo precoce foi aquele que apresentou as maiores janelas de semeadura e as menores áreas de alto risco.

$\mathrm{Na}$ segunda metodologia (2M), verificou-se a maior segurança na análise do risco de déficit hídrico com as duas fases críticas (I e III), pois a 'janela de semeadura' foi reduzida para 10 decêndios favoráveis à semeadura.

$\mathrm{Na}$ Figura 4, ilustrou-se os resultados da segunda metodologia (2M), com o mapa das zonas de risco climático para a soja de ciclo médio, em solo Tipo 3, semeada no decêndio de 15 de novembro.

A espacialização dos dados indicou que a maior parte da área do Cerrado classificada como zona de baixo risco climático localizou-se nos Estados de Goiás, Mato Grosso, São Paulo, Tocantins e o Distrito Federal; ou, ao contrário, a maioria das áreas de alto e médio risco situou-se nos Estados da Bahia, Maranhão, Mato Grosso do Sul, Minas Gerais, Piauí e São Paulo. Evangelista et al. (2017) afirmaram é que o sul do Piauí e o oeste da Bahia são sub-regiões produtoras de soja, mas submetidas a elevadas e frequentes restrições hídricas.

A redução de área da zona de baixo risco pode ser facilmente verificada no Estado do Maranhão; isto é, na primeira metodologia $(1 \mathrm{M})$ observou-se que apenas algumas manchas foram classificadas como zonas de médio e alto risco no Estado do Maranhão (Figura 3), enquanto que na segunda metodologia (2M), a maior parte do Cerrado maranhense foi classificada de médio e alto risco climático (Figura 4).

Reitera-se que, em ambas as abordagens metodológicas $(1 \mathrm{M}$ e $2 \mathrm{M})$, as áreas de alto risco situaram-se nas franjas de transição entre biomas, principalmente entre o Cerrado e a Caatinga (Figura 3 e 4); logo, podem-se sugerir estudos mais detalhados que melhor caracterizem os riscos agroclimáticos nas regiões de ecótonos.

Nesta segunda metodologia (Fase I e III críticas), no que se refere aos 1.380 municípios estudados no bioma Cerrado, foram recomendados 1.172 municípios para a semeadura da soja de ciclo precoce em solo do Tipo 2; e, em solo do Tipo 3 foram recomendados 1.122 municípios. Para a cultivar de ciclo médio em solo Tipo 2 foram recomendados 1.168 municípios, mas em solo do Tipo 3 foram recomendados 1.212 municípios. E, para cultivar da soja de ciclo tardio foram recomendados 1.161 municípios e 1.205 em solos do Tipo 2 e 3 , respectivamente (Tabela 6).

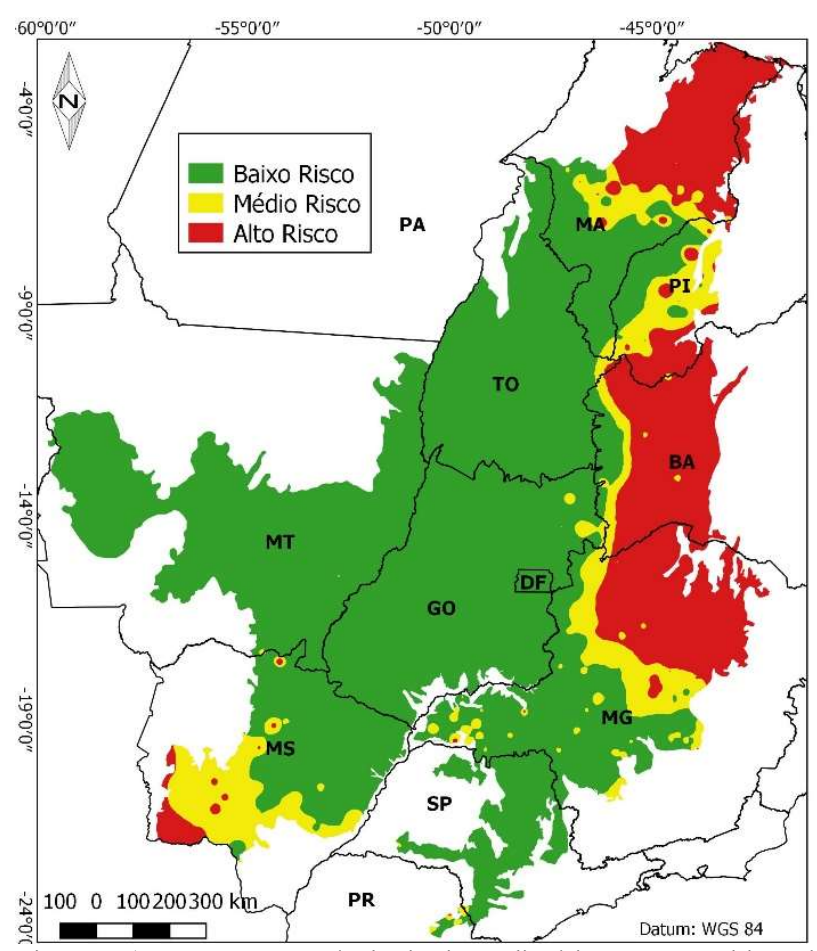

Figura 4. Zoneamento agrícola de risco climático para a cultivar de soja de ciclo médio (125 dias), semeada em solos com a capacidade de água disponível no solo de $75 \mathrm{~mm} / \mathrm{m}$ (Tipo 3), no decêndio de 15 de novembro, pela metodologia que considerou o déficit hídrico crítico nas Fases I e III. Fonte: Elaboração própria (2019)

Figure 4. Climatic risk agricultural zoning for medium-cycle soybean cultivation (125 days), planted on soils with soil available water capacity of $75 \mathrm{~mm} / \mathrm{m}$ (Type 3) in the december 15, methodology that considered the critical water deficit in Phases I and III.

\subsection{Comparação entre as duas metodologias}

$\mathrm{Na}$ Tabela 5, apresentaram-se as diferenças de área das zonas de risco climático entre as duas metodologias, em percentual.

Os valores positivos significaram que as áreas de riscos calculadas na primeira abordagem metodológica $(1 \mathrm{M})$ foram maiores que na segunda abordagem $(2 \mathrm{M})$ ou, ao contrário, os valores negativos significaram que as áreas calculadas na segunda abordagem foram maiores; e, o valor 0 (zero) significou que as áreas de risco calculadas em ambas metodologias foram iguais ( $\mathrm{Ad} \%=\mathrm{A} 1 \mathrm{M} \%-\mathrm{A} 2 \mathrm{M} \%)$.

A maior diferença $(38 \%)$ ocorreu na data de semeadura de 05 de outubro, verificada na classe de baixo risco, para a soja de ciclo médio cultivada em solo do Tipo 3 (Tabela 5); todavia, sendo a diferença um valor positivo, isso significa que a primeira metodologia $(1 \mathrm{M})$ apresentou zona de baixo risco maior que a segunda metodologia (2M); ou, ao contrário, na segunda metodologia, a área da zona de baixo risco foi $38 \%$ menor que na primeira metodologia, e ao mesmo tempo verificou-se que as zonas de médio e alto risco aumentaram $10 \%$ e $28 \%$, respectivamente.

Comparativamente, na segunda metodologia, as áreas de baixo risco foram menores; portanto, reitera-se que a segunda metodologia (Fase I e III críticas) mostrou-se mais restritiva que a primeira metodologia (Tabela 5).

Neste sentido, quanto aos municípios, na primeira metodologia (Fase I crítica), o número de municípios 
recomendados foi maior que na segunda abordagem (Fase I e Fase III críticas), por exemplo, na primeira abordagem foram recomendados 1.252 municípios para soja de ciclo precoce em solo do Tipo 2, enquanto foram recomendados 1.172 municípios na segunda abordagem (Tabela 6).

Em geral, a cultura da soja foi recomendada para a maioria dos munícipios pertencentes ao bioma Cerrado, principalmente para cultivo em solos do Tipo 3, com maior capacidade de água disponível $(\mathrm{CAD}=75 \mathrm{~mm} / \mathrm{m})$; exceto para a soja de ciclo precoce, considerando a nova abordagem (2M), verificou-se uma diminuição da quantidade de municípios recomendados em solo Tipo 3, isto é, 1.172 municípios foram recomendados para a soja precoce em solo do Tipo 2, e 1.122 municípios em solo Tipo 3. Diferentes fatores podem ter interatuado para este resultado sugerindose assim avaliação mais detalhada para a soja de ciclo precoce no bioma Cerrado, quando considerada a segunda metodologia (2M).

Tabela 5. Diferença percentual de área das classes de risco climático entre a primeira e a segunda metodologia no bioma Cerrado $($ Ad $\%=$ $\mathrm{A} 1 \mathrm{M} \%-\mathrm{A} 2 \mathrm{M} \%$ ).

Table 5. Percentage difference of area of climatic risk classes between the first and second methodology in the Cerrado biome $($ Ad $\%=$ $\underline{\mathrm{A} 1 \mathrm{M} \%-\mathrm{A} 2 \mathrm{M} \%)}$

\begin{tabular}{|c|c|c|c|c|c|c|c|c|c|c|c|c|c|c|}
\hline \multirow{4}{*}{$\begin{array}{c}\text { Ciclo } \\
\text { da } \\
\text { Cultivar }\end{array}$} & \multirow{4}{*}{$\begin{array}{c}\text { Tipo } \\
\text { de } \\
\text { Solo }\end{array}$} & \multirow{4}{*}{$\begin{array}{c}\text { Classe de } \\
\text { Risco }\end{array}$} & \multicolumn{12}{|c|}{ Datas de Semeaduras } \\
\hline & & & \multicolumn{3}{|c|}{ Outubro } & \multicolumn{3}{|c|}{ Novembro } & \multicolumn{3}{|c|}{ Dezembro } & \multicolumn{3}{|c|}{ Janeiro } \\
\hline & & & 5 & 15 & 25 & 5 & 15 & 25 & 5 & 15 & 25 & 5 & 15 & 25 \\
\hline & & & \multicolumn{12}{|c|}{ Diferença de Área entre a Primeira e Segunda Metodologia, em Percentual } \\
\hline \multirow{6}{*}{ Precoce } & \multirow{3}{*}{$\mathrm{T} 2$} & Baixo & 25 & 16 & 12 & 0 & 1 & 8 & 14 & 4 & 1 & 2 & 0 & 0 \\
\hline & & Médio & -7 & -2 & 0 & 1 & 3 & 1 & 0 & -1 & 0 & 0 & 2 & 0 \\
\hline & & Alto & -18 & -13 & -12 & -1 & -4 & -9 & -14 & -3 & -1 & -2 & -2 & 0 \\
\hline & \multirow{3}{*}{ T3 } & Baixo & 34 & 20 & 8 & 0 & 2 & 4 & 4 & 4 & 1 & 0 & 0 & 0 \\
\hline & & Médio & -9 & -1 & 4 & 3 & 3 & 0 & 0 & -1 & -1 & 0 & 0 & 0 \\
\hline & & Alto & -25 & -19 & -12 & -3 & -5 & -4 & -4 & -3 & 0 & 0 & 0 & 0 \\
\hline \multirow{6}{*}{ Médio } & \multirow{3}{*}{$\mathrm{T} 2$} & Baixo & 34 & 18 & 4 & 1 & 2 & 4 & 4 & 3 & 1 & 0 & 0 & 0 \\
\hline & & Médio & -9 & 0 & 3 & 4 & 3 & 1 & 0 & -1 & 0 & 0 & 0 & 0 \\
\hline & & Alto & -25 & -24 & -7 & -5 & -5 & -5 & -4 & -2 & -1 & 0 & 0 & 0 \\
\hline & \multirow{3}{*}{ T3 } & Baixo & 38 & 21 & 10 & 2 & 6 & 5 & 5 & 4 & 1 & 0 & 0 & 0 \\
\hline & & Médio & -10 & 1 & 6 & 4 & 0 & 0 & -1 & -1 & 0 & 0 & 0 & 0 \\
\hline & & Alto & -28 & -16 & -16 & -6 & -6 & -5 & -4 & -3 & -1 & 0 & 0 & 0 \\
\hline \multirow{6}{*}{ Tardio } & \multirow{3}{*}{$\mathrm{T} 2$} & Baixo & 34 & 18 & 2 & 3 & 4 & 4 & 5 & 4 & 1 & 0 & 0 & 0 \\
\hline & & Médio & -7 & 0 & 6 & 3 & 0 & 0 & -1 & -2 & 0 & 0 & 0 & 0 \\
\hline & & Alto & -27 & -18 & -8 & -6 & -4 & -4 & -4 & -2 & -1 & 0 & 0 & 0 \\
\hline & \multirow{3}{*}{ T3 } & Baixo & 37 & 20 & 6 & 6 & 6 & 5 & 4 & 4 & 1 & 0 & 0 & 0 \\
\hline & & Médio & -7 & 4 & 8 & 1 & -1 & -1 & 0 & -1 & -1 & 0 & 0 & 0 \\
\hline & & Alto & -30 & -24 & -14 & -7 & -5 & -4 & -4 & -3 & 0 & 0 & 0 & 0 \\
\hline
\end{tabular}

Tabela 6. Quantidade de municípios recomendados pela primeira (1M) e segunda (2M) metodologia.

Table 6. Number of municipalities recommended by the first $(1 \mathrm{M})$ and second $(2 \mathrm{M})$ methodology.

\begin{tabular}{|c|c|c|c|c|c|c|}
\hline \multirow{4}{*}{$\begin{array}{c}\text { Ciclo } \\
\text { da Cultivar }\end{array}$} & \multirow{4}{*}{$\begin{array}{l}\text { Tipo de } \\
\text { Solo }\end{array}$} & \multicolumn{4}{|c|}{ Metodologias } & \multirow{4}{*}{$\begin{array}{c}\text { Diferença do número } \\
\text { de municípios }\end{array}$} \\
\hline & & $1 \mathrm{M}$ & $2 \mathrm{M}$ & $1 \mathrm{M}$ & $2 \mathrm{M}$ & \\
\hline & & \multicolumn{4}{|c|}{ Número de municípios } & \\
\hline & & \multicolumn{2}{|c|}{ Recomendados } & \multicolumn{2}{|c|}{ Sem recomendação } & \\
\hline \multirow{2}{*}{ Precoce } & $\mathrm{T} 2$ & 1252 & 1172 & 128 & 208 & $|80|$ \\
\hline & T3 & 1272 & 1122 & 108 & 258 & $|150|$ \\
\hline \multirow{2}{*}{ Médio } & $\mathrm{T} 2$ & 1231 & 1168 & 149 & 212 & $|63|$ \\
\hline & T3 & 1289 & 1212 & 91 & 168 & |77| \\
\hline \multirow{2}{*}{ Tardio } & $\mathrm{T} 2$ & 1221 & 1161 & 159 & 219 & $|60|$ \\
\hline & T3 & 1271 & 1205 & 109 & 175 & | 66| \\
\hline
\end{tabular}

\section{DISCUSSÃO}

O zoneamento de risco climático da soja no bioma Cerrado simplesmente indicou a menor probabilidade de perdas por déficit hídrico, considerando três ciclos de cultivares, dois tipos de solo, 12 decêndios de semeadura e duas metodologias distintas; porém, diversos outros fatores ambientais, agronômicos e econômicos podem afetar o desempenho da cultura (FARIAS et al., 2001). Logo, áreas com maior CAD, provavelmente possuem menor risco climático.
Ademais, áreas classificadas como de médio risco climático podem ser enquadradas como de baixo risco climático, caso as práticas de manejo do solo e da cultura que permitem a planta superar curtos períodos de adversidade climáticas (FARIAS et al, 2001), por exemplo, seguir a recomendações de correção e fertilização do solo e plantio direto.

Para Cunha et al. (2001) a indicação do mesmo período de semeadura, para determinados locais, não implica em igual nível de risco, pois solos de maior capacidade de 
armazenamento de água garantem, em épocas de estiagem, as necessidades hídricas da cultura por período maior.

Segundo Andrade Júnior et al. (2007), o zoneamento agrícola de risco climático permite definir regiões climáticas favoráveis para o cultivo agrícola, a partir do conhecimento das variabilidades climáticas locais (precipitação, evapotranspiração) e épocas adequadas de semeadura, como forma de diminuir os efeitos causados pelas variações na distribuição de chuvas e de sua espacialização regional, por meio de sistema de informação geográfica.

Deve-se salientar, ainda, que o zoneamento agrícola de risco climático apresenta as áreas favoráveis ao cultivo, e não áreas de aptidão agrícola propriamente dita, pois nem todas as áreas favoráveis são aptas ao cultivo; além da disponibilidade hídrica, outros fatores devem ser considerados para avaliar a viabilidade da exploração da cultura com sucesso numa dada região (FARIAS et al., 2007).

Destaca-se ainda, que as áreas de transição apresentam ampla variação climática e do meio físico, formando fitofisionomias diferenciadas inseridas em distintas unidades ecológicas nas regiões de transição (SILVA et al., 2006). Logo, essa ampla variabilidade contribui para que haja mais zonas de alto e médio risco nessa área.

Para Santos; Martins (2016) o Zarc é um importante instrumento técnico-científico voltado para a questão das perdas da agricultura, conforme decisão, planejamento e execução dos órgãos governamentais para política agrícola. Além disso, o programa precisa de aprimoramentos nos seus aspectos metodológicos e operacionais, devendo estar mais bem articulado com outros zoneamentos oficiais, como o Zoneamento Ecológico-Econômico.

Estudos futuros mais detalhados podem ser sugeridos para as ecorregiões do Cerrado, porque elas apresentam características edafoclimáticas próprias (ARRUDA et al., 2008; FARIAS et al., 2001); também, pode-se levar em consideração outras variáveis, como relevo e áreas não agricultáveis (ASSIS et al., 2016; COUTO JUNIOR et al., 2010; SILVA et al., 2017).

\section{CONCLUSÕES}

A simulação de modelo agrometeorológico de balanço hídrico associado às técnicas de geoprocessamento permitiu analisar, no tempo e no espaço, as relações solo-clima-planta, elaborar zoneamento agrícola de risco climático visando a recomendar as épocas mais favoráveis à semeadura da cultura de soja no bioma Cerrado.

A comparação entre as duas metodologias mostrou que a abordagem que considera crítica duas fases da cultura de soja, a Fase I - germinação e desenvolvimento inicial - e a Fase III - floração e enchimento dos grãos - é mais rigorosa, restringe o número de ocorrência de decêndios favoráveis à semeadura principalmente no início do período chuvoso, reduz a área da zona agrícola de baixo risco climático e, em consequência, apresenta menor probabilidade de perdas por estresse hídrico no bioma Cerrado.

As zonas agrícolas de baixo risco climático localizam-se na área central do bioma Cerrado e, também, na área de transição entre os biomas do Cerrado e Amazônia; enquanto as zonas de médio e alto risco situam-se principalmente nas áreas de transição entre os biomas - Cerrado e Caatinga - e, também, entre o Cerrado e o Pantanal.
Em geral, os solos com maior capacidade de água disponível apresentam menor risco de déficit hídrico, porque garantem as necessidades da cultura por maior período.

As informações do estudo de zoneamento agrícola de risco climático contribuem para as tomadas de decisões de órgãos planejadores, financiadores e produtores, além de subsidiarem a formulação de novas políticas públicas que visam ao aumento da sustentabilidade do cultivo da soja no bioma Cerrado.

\section{AGRADECIMENTOS}

Ao Laboratório de Biofísica Ambiental da EMBRAPA Cerrados.

\section{REFERÊNCIAS}

ALLEN, R.G.; PEREIRA, L. S.; RAES, D.; SMITH, M. Crop evapotranspiration: guidelines for computing crop water requirements. Rome: FAO, 1998. 300 p. (FAO. Irrigation and Drainage Paper, 56).

ALVARES, C. A.; STAPE, J. L.; SENTELHAS, P. C.; GONÇALVES, J. L. M.; SPAROVEK, GERD. Meteorologische Zeitschrift, Berlin, vol. 22, n. 6, p. 711 - 728, 2013 . DOI: https://dx.doi.org/10.1127/09412948/2013/0507.

ANDRADE JÚNIOR, A. S.; BASTOS, E. A.; SILVEIRA JÚNIOR, D. M. Zoneamento de risco climático. In: CARDOSO, M. J. \& ATHAYDE SOBRINHO, C. (Org.). O milho no Meio-Norte do Brasil: Estratégias Básicas do Manejo. Teresina: Embrapa Meio-Norte, 2007, p. 343-368.

ARIAS, D.; MENDES, P.; ABEL, P. Revisão rápida e integrada da gestão de riscos agropecuários no Brasil: caminhos para uma visão integrada. Brasília: Banco Mundial, 2015. 76 p.

ARRUDA, M. B.; PROENÇA, C. E. B.; RODRIGUES, S.; MARTINS, E. S.; MARTINS, R. C.; CAMPOS, R. N. Ecorregiões, unidades de conservação e representatividade ecológica do bioma Cerrado. In: SANO, S.; ALMEIDA, S. P. (Org.). Cerrado: ecologia e flora. Embrapa, 2008. v. 1, p. 229-270.

ASSIS, T., MARTINS, E. S.; COUTO JÚNIOR, A. F. Relações entre o relevo e agroecossistemas na ecorregião Paraná-Guimarães. Revista Brasileira de Geografia Física, Recife, v. 9, n. 2, p. 498-510, 2016.

BARON, C.; CLOPES, A. Sistema de Análise Regional dos Riscos Agroclimáticos (SARRAMET/SARRAZON). Centro de Cooperação Internacional em Pesquisa Agronômica para o Desenvolvimento. França: SARRA. CIRAD, 1996.

BRASIL. Congresso Nacional. Lei $\mathbf{N}^{\mathbf{0}}$ 12.651, de 25 de maio de 2012. Dispõe sobre a proteção da vegetação nativa e dá outras providências. Disponível em: http://www.planalto.gov.br/ccivil_03/_Ato20112014/2012/Lei/L12651.htm. Acesso em 12.fev.2017.

BRASIL. Ministério da Agricultura, Pecuária e Abastecimento. Instrução Normativa $\mathbf{N}^{\circ} 2$, de 9 de outubro de 2008. Descrições das características específicas dos diferentes tipos de solos, atualmente utilizadas no zoneamento agrícola de risco climático. Disponível http://www.agricultura.gov.br/assuntos/riscos- 
seguro/risco-agropecuario/portarias. Acesso em: 28.fev. 2017

BRASIL. Ministério da Agricultura, Pecuária e Abastecimento. Zoneamento agrícola de risco climático. (2017). Disponível em: http://www.agricultura.gov.br/assuntos/riscosseguro/risco-agropecuario/zoneamento-agricola. Acesso em 12.fev.2017

CADAVID GARCIA, E. A. O clima no Pantanal MatoGrossense. Corumbá: EMBRAPA-UEPAE Corumbá, 1984. 42 p. (Circular técnica, 14).

CARAMORI, P. H.; NITSCHE, P. R.; DEPPE, F.; LEITE, E. A.; TSUKAHARA, R. Y.; BORROZZINO, E. Agrometeorologia operacional no estado do Paraná. Agrometeoros, v. 24, n. 1, p. 65-70, 2016. DOI: http://dx.doi.org/10.31062/agrom.v24i1.24882

CARVALHO, H.P., DOURADO NETO, D., TEODORO, R.E.F., MELO, B. Balanço hídrico climatológico, armazenamento efetivo da água no solo e transpiração na cultura de café. Bioscience Journal, Uberlândia, v. 27, n. 2, p. 221-229, 2011.

CONAB_COMPANHIA ABASTECIMENTO.

NACIONAL DE Levantamento.

Acompanhamento da Safra Brasileira Grãos. Brasília, v. Oitavo 3, n. 8, p. 1-134, 2016. Disponível em: <http://www.conab.gov.br>. Acesso em: 10 maio 2016.

CONAB_COMPANHIA NACIONAL DE ABASTECIMENTO. Séries históricas: Soja. 2017. Disponível em: https://www.conab.gov.br/conteudos.php?a=1252\&Pa gina_objcmsconteudos=3\#A_objcmsconteudos. Acesso em: 15 out. 2017.

CORREIA, R. C.; KILL, L. H. P.; MOURA, M. S. B.; CUNHA, T. J. F.; JESUS JÚNIOR, L. A.; ARAÚJO, J. L. P. A região semiárida brasileira. In: VOLTOLINI, T. V. (Ed.). Produção de caprinos e ovinos no Semiárido. Petrolina: Embrapa Semiárido, 2011.

COUTO JUNIOR, A. F; VASCONCELOS, V.; CARVALHO JUNIOR, O. A.; MARTINS, E. S.; SANTANA, O. A.; FREITAS, L. F.; GOMES, R. A. T. Integração de parâmetros morfométricos e imagem ASTER para a delimitação das fitofisionomias da Serra da Canastra, Parque Nacional da Serra da Canastra, MG. Revista Brasileira de Geomorfologia, Brasília, v. 11, n. 1, p. 57-68, 2010. DOI: http://dx.doi.org/10.20502/rbg.v11i1.142

CUNHA, G. R., ASSAD, E. D. Uma visão geral do número especial da RBA sobre zoneamento agrícola no Brasil. Revista Brasileira de Agrometeorologia, Passo Fundo, v. 9, n. 3, p. 377-385, 2001.

DESCONTO, J. G. Aquecimento Global e a nova Geografia da Produção agrícola no Brasil. Posigraf, 2008. 84 p.

EMBRAPA_EMPRESA BRASILEIRA DE PESQUISA AGROPECUÁRIA. Soja em números (Safra 2016/2017). 2017. 1 p. Disponível em: $<$ https://www.embrapa.br/soja/cultivos/soja1/dadoseconomicos>. Acesso em: 12.fev. 2017.

EVANGELISTA, B. A.; SILVA, F. A. M.; SIMON, J.; CAMPOS, L. J. M.; VALE, T. M. Zoneamento de risco climático para determinação de épocas de semeadura da cultura da soja na região MATOPIBA. Palmas: Embrapa Pesca e Aquicultura, 2017. 44 p. (Boletim de pesquisa e desenvolvimento, 18)
FARIAS, J. R. B.; ASSAD, E. D.; ALMEIDA, I. R.; EVANGELISTA, B. A.; LAZZAROTTO, C.; NEUMAIER, N.; NEPOMUCENO, A. L. Caracterização de risco de déficit hídrico nas regiões produtoras de soja no Brasil. Revista Brasileira de Agrometeorologia, Passo Fundo, v. 9, n. 3, p. 415-421, 2001.

FARIAS, J. R. B., NEPOMUCENO, A. L., NEUMAIER, N. Ecofisiologia da soja. Circular Técnica, 48. Embrapa Soja. Londrina, 2007. 9p.

GUERRA, A. F.; ROCHA, O. C.; RODRIGUES, G. C., SOUZA, P. I. de M. D. E. Método de tanque classe A para irrigação da soja, cultivar Sambaíba, no Cerrado. Planaltina: Embrapa Cerrados, 2005. 3 p. (Comunicado técnico, 120).

IPCC_INTERGOVERNMENTAL PANEL ON CLIMATE CHANGE. A mudança do clima: a base das ciências físicas. Quarto relatório de avaliação do GT1 do IPCC. 2007. 25 p. Disponível em: <https://www.ipcc.ch/pdf/reports-nonUNtranslations/portuguese/ar4-wg1-spm.pdf $>$. Acesso em: 17.set.2015.

IPCC_INTERGOVERNMENTAL PANEL ON CLIMATE CHANGE. Climate Change 2014: synthesis report. Contribution of working groups I, II and III to the fifth assessment report of the intergovernmental panel on climate change IPCC, Geneva, Switzerland, 151 pp. 2014.

IPCC_INTERGOVERNMENTAL PANEL ON CLIMATE CHANGE. Intergovernmental Painel on Climate Change. Mudança do Clima 2014: Impactos, Adaptação e Vulnerabilidade: Sumário para Tomadores de Decisão. Grupo de trabalho II do IPCC. São Paulo, 2015.

MACIEL, G. F., AZEVEDO, P. V., ANDRADE JÚNIOR, A. S. Impactos do aquecimento global no zoneamento de risco climático da soja no estado do Tocantins. Engenharia Ambiental, Espírito Santo do Pinhal, v. 6, n. 3, p.141-154, 2009

MAPA_MINISTÉRIO DA AGRICULTURA PECUÁRIA E ABASTECIMENTO. Projeções do agronegócio, Brasil 2016/2017 a 2026/2027. Brasília, 2017. 125 p. Disponível

http://www.agricultura.gov.br/assuntos/politicaagricola/todas-publicacoes-de-politicaagricola/projecoes-do-agronegocio/projecoes-doagronegocio-2017-a-2027-versao-preliminar-25-0717.pdf. Acesso em 28.fev.2017.

MMA_MINISTÉRIO DO MEIO AMBIENTE. Monitoramento do desmatamento nos biomas brasileiros por satélite: monitoramento do bioma Cerrado, 2009-2010. Brasília. 2011. 65 p. Disponível em: http://www.mma.gov.br/estruturas/sbf_chm_rbbio/_a rquivos/relatoriofinal_cerrado_2010_final_72_1.pdf. Acesso em: 12.fev.2017.

PASSOS, M. L. V.; ZAMBRZYCKI, G. C.; PEREIRA, R. S. Balanço hídrico climatológico e classificação climática para o município de Balsas-MA. Revista Scientia Agraria, Curitiba, v. 18, n. 1, p. 83-89, 2017.

ROSSETTI, L. A. Zoneamento agrícola em aplicações de crédito e securidade rural no Brasil: aspectos atuariais e de política agrícola. Revista Brasileira de Agrometeorologia, Passo Fundo, v. 9, n. 3, p. 386-399, 2001. 
SANO, E. E.; ROSA, R.; BRITO, J. L. S.; FERREIRA, L. G. Mapeamento semidetalhado do uso da terra do Bioma Cerrado. Pesquisa Agropecuária Brasileira, Brasília, v. 43, n. 1, p. 153-156, 2008. DOI: http://dx.doi.org/10.1590/S0100-204X2008000100020

SANTOS, W. G.; MARTINS, J. I. F. O Zoneamento Agrícola de Risco Climático e sua contribuição à agricultura brasileira. Revista de Política Agrícola, v. 25, n. 3, p. 79-94, 2016.

SEDIYAMA, G. C.; MELO JUNIOR, J. C.; SANTOS, A. R.; RIBEIRO, A.; COSTA, M. H.; HAMAKAWA, P. J.; COSTA, J. M. N.; COSTA, L. C. Zoneamento agroclimático do cafeeiro (Coffea arabica L.) para o Estado de Minas Gerais. Revista Brasileira de Agrometeorologia, Passo Fundo, v. 9, p. 501-509, 2001.
SILVA, F. A. M. DA; SANTOS, K. DE S.; MARTINS, E. DE S.; EVANGELISTA, B. A.; MONTEIRO, J. E. B. A. Zoneamento pedoclimático para a semeadura simultânea do milho e da braquiária no estado de Goiás. Agrometeoros, v. 25, n. 1, p. 71-79, 2017. DOI: http://dx.doi.org/10.31062/agrom.v25i1.26268

SILVA, F. A. M., ASSAD, E.D., STEINKE, E.C., MULLER, A.G. Clima do bioma Cerrado. In: Alburqueque, A.C.S; Silva, A.G (Org.). Agricultura tropical: quatro décadas de inovações tecnológicas, institucionais e políticas. Embrapa Informação Tecnológica, 2008. p. 93-148.

SILVA, J. F.; FARIÑAS, M. R.; FELFILI, J. M.; KLINK, C. A. Spatial heterogeneity, land use and conservation in the Cerrado region of Brazil. Journal of Biogeography, Oxford, v. 33, n. 3, p. 536-548, 2006. DOI: https://dx.doi.org/10.1111/j.1365-2699.2005.01422.x 